\title{
Calibration procedure of hydraulic simulations for the microhabitat method
}

\author{
Ludovic Cassan ${ }^{1, *}$, Hélène Roux ${ }^{1}$, Dominique Courret $^{2}$ and Sylvain Richard ${ }^{2}$ \\ ${ }^{1}$ Institut de Mécanique des Fluides de Toulouse, IMFT, Université de Toulouse, CNRS - Allée du \\ professeur Camille SOULA 31400 Toulouse, France \\ ${ }^{2}$ Agence Française pour la Biodiversité, Pole Ecohydraulique, Allée du professeur Camille SOULA \\ 31400 Toulouse, France
}

\begin{abstract}
Hydropower plants can profoundly modify the natural morphology and hydrology of rivers and can alter the functionality of habitats for fish living and reproduction. In particular, hydropeaking leads to rapid and frequent changes of the hydrodynamic conditions and it is crucial to ensure aquatic habitat quality is maintained as much as possible during these periods. One present method to determine mitigation measure (minimum and maximum flow, rate of change) is to perform hydraulic simulations in $1 \mathrm{D}$ or $2 \mathrm{D}$ in the range of flow variation and to evaluate habitat quality for fish with the microhabitat method. The hydraulic model calibration has to be conducted carefully since the model has to reproduce precisely the hydraulic conditions from low to high flow rates (up to several times the mean flow of the rivers). Within this range, the friction coefficient can evolve greatly because at low flows the size of roughness elements become comparable to the water depth.. This phenomenon is observed by performing the modelling and the calibration at 2 stations on a river in French Pyrenees with different cross section shapes, one with progressive overflowing of some banks with large blocks and the other one without such phenomena. Thanks to field measurements of water levels at low and high discharge, the calibration process has shown that the friction coefficient can be multiplied by 2 as a function of the discharge. The paper proposes a methodology to evaluate the most appropriate tool. As water depth is concerned, the 2D simulations (TELEMAC 2D) provide similar results to those obtained with 1D (HEC-RAS) because flow remains unidirectional. Then a sensitivity analysis is carried out to estimate the uncertainty on the fish habitat outputs for a fish species (brown trout in the present study) resulting from several widely used friction laws. These friction laws can lead to different conclusions about habitat suitability depending on the calibrated coefficient. Finally, to perform relevant habitat modelling, it is necessary to measure water levels at several discharges and to describe accurately the spatial variability of roughness height.
\end{abstract}

\section{Introduction}

Anthropic activities can either decrease or increase the natural discharge by withdrawal or hydropeaking respectively. But the aquatic habitat depends on the hydrology and the discharge flowing in the river and the impact on ecosystem is a crucial issue for river management. Several approaches are possible to evaluate these issues and one of them is

* Corresponding author: $\underline{1 \mathrm{cassan} @ \text {,imft.fr }}$ 
the hydraulic modelling which has the advantage to simulate the spatial variability of the hydraulic variables (velocity, water depth) and to be valid for a large range of discharges $[1,2]$. As a consequence, hydraulic modeling can help for setting ecological minimum flowrate but also knowing overbank flow. When hydropeaking occur, some risks for fish populations exist: stranding-trapping of alevins and dewatering of redds consecutive to flow reduction, forced drifting of alevins due to flow increase. Then the hydraulic modeling is an efficient tool to follow the flow modification, to assess these risks and then determining mitigation measures such as minimum flow, maximum rate of change or a maximum discharge. To be relevant the hydraulic model has to be coupled with biological model which indicates the suitability to hydraulic parameters of each fish species and life stages or activities (reproduction, alevins, juvenile, adult). This coupling is the base of the microhabitat method which is integrated in software such as EVHA [3]. The purpose of this paper is to estimate the abilities of different kinds of modeling (1D/2D/friction laws) to well computed habitat variation due to hydrology [4]. In particular, we will focus on the calibration procedure which is specific because of the small ratio between water depth and roughness diameter. Moreover the model has to be relevant for both low and high discharge.

The first part of the results will deal with the different formulae available in numerical tools to take into account bed friction. The ranges of parameters are extracted from a case study on a French river for two stations which have cross sections of different characteristics. Afterward, a study on fish habitat is performed in these two stations using the microhabitats method, to estimate the sensitivity of results to hydraulic calibration method (at low, intermediate or high discharge, linear interpolation or physically based model).

\section{Material and Method}

\subsection{Case studies}

Two reaches have been studied to illustrate the influence of hydraulic modelling on the habitat variable. These two stations are located on the same river called Vicdessos in French Pyrenees. The studied river section is usually bypassed by a hydroelectric scheme, but will be influenced soon by hydropeaking from upstream plant during several years due to maintenance work at the downstream plant of the scheme [5]. The minimum discharge is fixed to $1.6 \mathrm{~m}^{3} / \mathrm{s}$. We will also focus on the maximum discharge possibly reached by the plant. This discharge is evaluated to $16 \mathrm{~m}^{3} / \mathrm{s}$.
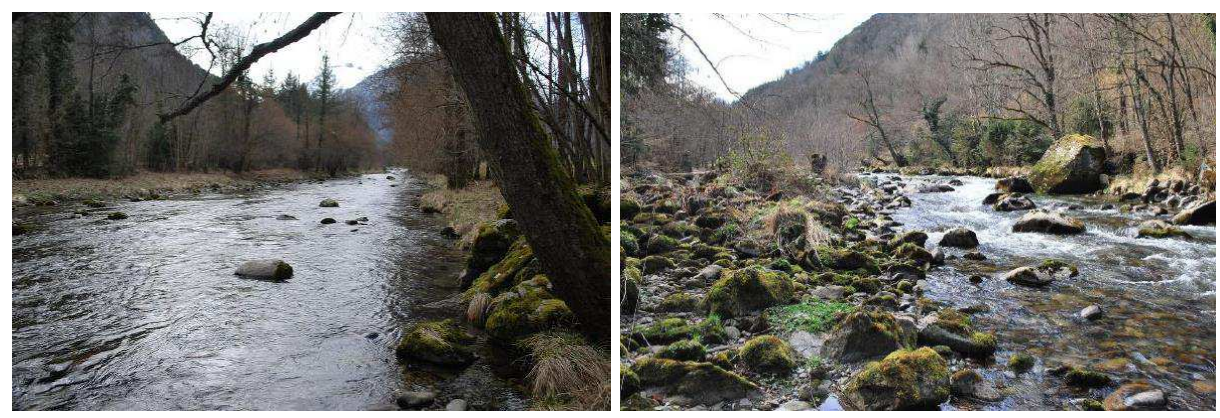

Figure 1 : Photographs of the two selected station: station 1 (left) and station 2 (right) [5]. 
The two stations named station 1 and 2 are selected because they are typical of the river configurations in the section. Indeed for each station, $40 \%$ of the longitudinal profiles have similar width, granulometry, slope and overbanks [5]. It can be noticed that the hydromorphology of the stations 1 and 2 are quite different (figure 1). In the first station, the main channel is almost trapezoidal and the free surface width increases regularly when the water depth is increasing. The granulometry distribution is homogenous on the bed and banks. In the second station, some banks with large blocks are likely to be submerged with moderate discharge. An averaged slope of 0.01 is measured for both stations. In a first part of results, the slope will be used to evaluate the influence of bed friction law considering manning-strickler equation and averaged water depth on at the station.

\subsection{Numerical modelling}

The topography and bathymetry of the stations are extracted from a previous study carried out by [5]. For the present study, we use the bathymetry incorporated in the two triangular meshes presented in the figure 2 . To refine and improve these meshes, a large number of measurement points are made in the zone with large emergent blocks. As the purpose of our work is to evaluate models independently of the measurement quality, the $1 \mathrm{D}$ model is built by using the topography of the $2 \mathrm{D}$ meshes. The cross sections are separated by $10 \mathrm{~m}$ and interpolated with $2 \mathrm{~m}$ distance (figure 2).

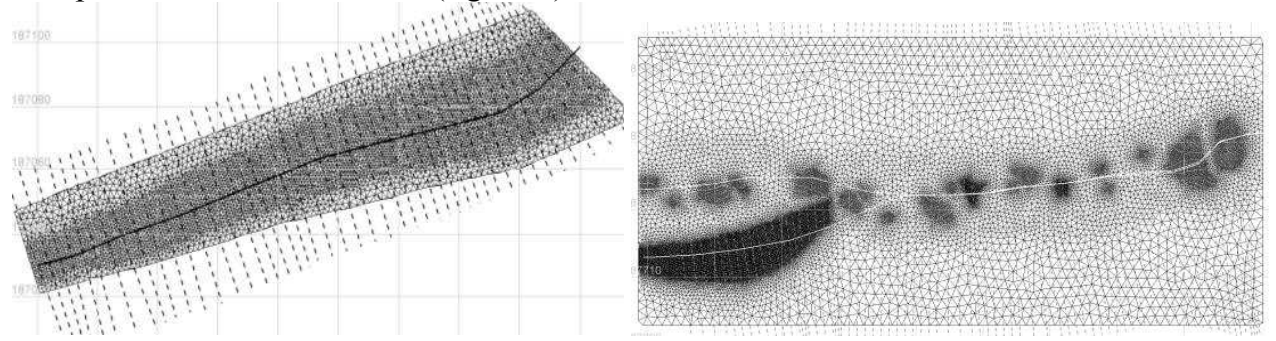

Figure 2 : Mesh for shallow water simulations of the station 1 (left) and station 2 (right). Dash lines are $1 \mathrm{D}$ cross sections. Solid lines are used for drawing longitudinal profiles.

To solve the shallow water equation, we performed simulations by $1 \mathrm{D}$ and $2 \mathrm{D}$ methods with the geometry described above. For 1D computation, the HEC-RAS software is used in steady state and subcritical regime. The bed friction can be described either by a constant Manning coefficient $n$ or a roughness weigth $k$. To obtain a transversal distribution of velocity, the transversal section is divided into 19 intervals corresponding to a length of approximately $1-2 \mathrm{~m}$ (station 1 ) and $3 \mathrm{~m}$ (station 2). The detail of the method can be found in the HEC-RAS reference manual [6].

The 2D computations are achieved with the TELEMAC 2D software based on the finite element method. A turbulence model (k- $\varepsilon$ model) is used to better describe the velocity field in the vicinity of emergent blocks. Unsteady calculations are made during 3000 seconds with a time step equals to 0.1 seconds. For each calculation, it is checked that the steady state solution is obtained.

For both kind of modelling the boundary conditions are identical: a rating curve at the downstream end and a constant discharge upstream. The rating curves are given by the water depth measurements used for the calibration (see next part). The friction coefficients ( $n$ or $k$ ) are uniform for the whole computation domain. 


\subsection{Calibration}

The water levels were measured along the longitudinal profiles for the two extremum discharges $\left(1.6\right.$ and $\left.16 \mathrm{~m}^{3} / \mathrm{s}\right)$ verified by gauging with an acoustic doppler profiler. The measurements are made at the left and right banks if a transversal variation is observed; this explains the measurement distribution on figure 3. The determination of the friction coefficient was done with the 2D simulations. In this study, we focused on the influence of the hydraulic calibration method on habitat simulations. As a consequence a uniform value is sufficient and the same coefficient is used for both 1D and 2D models.

At station 1, the figure 3 shows that a Manning coefficient of 0.066 and 0.045 allows reproducing the water levels for respectively 1.6 and $16 \mathrm{~m} 3 / \mathrm{s}$. The $1 \mathrm{D}$ and $2 \mathrm{D}$ model provide very close results because the channel is almost straight with no overbank flow. Therefore the flow is unidirectional, as the friction coefficient is constant and independent of water depth, the 1D and 2D equations are identical (excepted for the turbulence model).

At station 2, Manning coefficients of 0.05 (high flow) and 0.1 (low flow) can calibrate the $2 \mathrm{D}$ model. For this station, it is needed to consider separately the left and right side of the channel at the upstream part (see also figure 2). A small discrepancy between 1D and $2 \mathrm{D}$ model is noticeable. At the upstream part, the 1D assumption of a uniform transversal water level can easily explain the difference because the 2D model provides a water level difference that can reach $15 \mathrm{~cm}$. To improve the $1 \mathrm{D}$ model, another calibration could have been made but as explained before we prefer considering a general case i.e a uniform coefficient for 1D and 2D models.
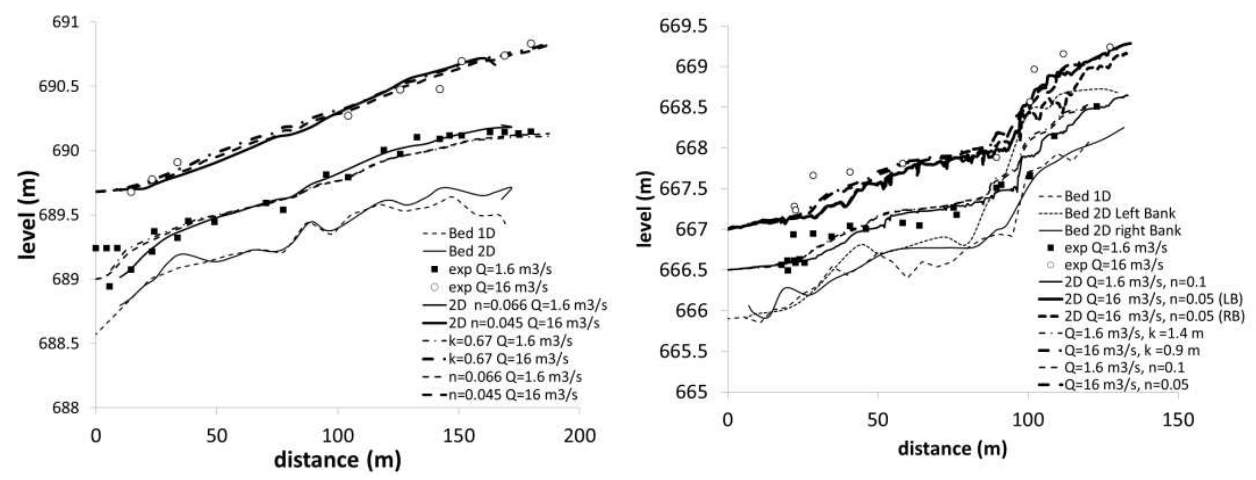

Figure 3 : Longitudinal profiles of water level simulated and measured for station 1 (left) and station 2 (right).

\subsection{Fish habitat modelling}

The microhabitat method needs a quantification of the suitability of hydraulic parameters for each fish species and life stages or activities (biological model). Here three life stages of brown trout (adult, juvenile and alevin) are considered because it is the species found in the river studied.

The suitability curves express the preference toward velocity $\left(S_{v}\right)$, water depth $\left(S_{h}\right)$ and nature of substratum. They can vary from 0 to 1,1 being for the favorable hydraulic conditions. In the present study, the substratum is not considered because of the lack of data. The chosen biological models are extracted from the software EVHA [3] which has compiled results of several former studies. The total suitability of one station is computed by integrating the product $S_{v}{ }^{*} S_{h}$ over the entire area. Then a weighted usable area (WUA) is defined by the following formula: 


$$
W U A=\sum a_{i} S_{v} S_{h}
$$

Where $a_{i}$ is the area of one interval between two cross sections. The previous formula is given in a discrete term because the simulation results are rasterized by square of $a_{i}$ $\left(0.2 * 0.2 \mathrm{~m}^{2}\right)$. To compare two different stations, WUA is normalized to provide the equivalent WUA for a 1 meter river length. Thanks to the hydraulic model, the WUA can be computed for the range of discharge between 0.1 and $16 \mathrm{~m}^{3} / \mathrm{s}$.

\section{Results}

\subsection{Bed friction laws}

In a first step, the influence of the fiction laws on habitat values is evaluated in an ideal case of a uniform flow in an infinitely wide channel. To be coherent with the presented river applications, the slope is fixed to 0.01 for the both stations. We tested 3 formula for bed friction based on logarithmic law $[7,8,9]$ with experimentally calibrated coefficients. We focus on the laws available in modelling softwares commonly used for habitat studies. Details on the laws are given in the table 1.

The relationship between discharge, velocity and water depth is computed from the Manning equation. An equivalent roughness height $k$ is calibrated for each law considering the measurements at low and high discharges. The results are provided in the table 2.

The calibration of the friction law shows that the roughness height strongly depends on the formulation used. The Limerinos law appears to provide the closest values to the observed granulometry. The high variability of the results is probably due to the difference between the calibration domains of formulas: sand for [7], natural river flow for [8], graveland boulder- bed streams for [9]. Although the friction laws can take into account the friction dependency on water level, they needed calibration because of the spatially heterogeneous distribution of the granulometry between main channel and banks.

Table 1: Coefficients of the studied friction laws.

\begin{tabular}{|l|c|l|}
\hline reference & Formula & Software \\
\hline Nikuradse [7] & $n=\frac{h^{1 / 6}}{18 \log _{10}\left(12.27 \frac{h}{k}\right)}$ & $\begin{array}{l}\text { HEC-RAS/ } \\
\text { TELEMAC 2D }\end{array}$ \\
\hline Limerinos [8] & $n=\frac{0.113 h^{1 / 6}}{2 \log _{10}\left(\frac{h}{k}\right)-1.16}$ & EVHA \\
\hline Ferguson [9] & $\sqrt{\frac{8}{f}}=\frac{6.5 * 2.5(h / k)}{\left[6.5^{2}+2.5^{2}(h / k)^{5 / 3}\right]^{1 / 2}}$ & \\
\hline
\end{tabular}

Table 2 : Equivalent roughness height $\mathrm{k}(\mathrm{m})$ calibrated at the 2 stations and for each discharge

\begin{tabular}{|l|c|c|c|c|}
\hline & $\begin{array}{l}\text { Station 1 } \\
\mathrm{Q}=1.6 \mathrm{~m}^{3} / \mathrm{s}\end{array}$ & $\begin{array}{c}\text { Station 1 } \\
\mathrm{Q}=16 \mathrm{~m}^{3} / \mathrm{s}\end{array}$ & $\begin{array}{c}\text { Station 2 } \\
\mathrm{Q}=1.6 \mathrm{~m}^{3} / \mathrm{s}\end{array}$ & $\begin{array}{c}\text { Station 2 } \\
\mathrm{Q}=16 \mathrm{~m}^{3} / \mathrm{s}\end{array}$ \\
\hline Nikuradse [6] & 0.68 & 0.66 & 1.4 & 0.87 \\
\hline Limerinos [7] & 0.21 & 0.19 & 0.43 & 0.26 \\
\hline Fergusson [8] & 0.010 & 0.011 & 0.04 & 0.016 \\
\hline
\end{tabular}


For the station 1 where the channel bed shape is regular, a logarithmic law allows estimating accurately the variation of $n$ with the water depth. On the other hand, the station 2 (with the ideal case of 1D uniform condition) shows that the experimental Manning cannot be simply described. Manning variations are due to both water level changes and bathymetry including stones of larger diameter at overbanks. As a consequence, it seems that the most accurate strategy to simulate intermediate discharges is to interpolate linearly Manning coefficient between the values calibrated at low and high discharge, to integrate all the phenomena. However in most cases, it could be difficult to calibrate the model for the extremum discharge. Therefore in the next part, we will evaluate the sensitivity of the habitat value for the various calibration strategies: calibration with 1 or 2 points, $1 \mathrm{D}$ vs $2 \mathrm{D}$, $n$ interpolation vs logarithmic laws.
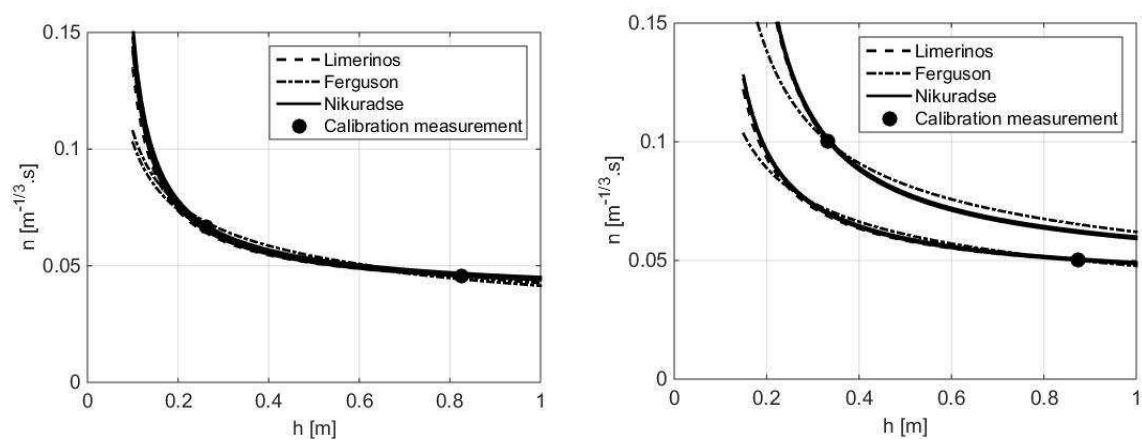

Figure 4 : Manning coefficients from logarithmic laws as a function of water depth for a uniform flow $(\mathrm{S}=0.01)$. Comparison with the calibrated values from station 1 (left) and station 2 (right).

\subsection{Sensitivity of habitat modelling}

Overall, the curves of WUA for the 3 life stages of trout show the same trend at the 2 stations: from low to high flow, values of WUA first increase, reach a maximum and then decrease more or less rapidly (figure 5 and figure 6). Discharges corresponding to maximum values of WUA are commonly higher for adults than for juveniles and for fry. When the discharge increases the WUA is reduced which is explained by the increase of velocity and water depth in the most part of the station.

The curves of WUA are sensitive to the calibration procedure of hydraulic simulations. For instance, at the 2 stations and at $Q=7 \mathrm{~m}^{3} / \mathrm{s}$, the WUA differs by a factor of about 2 for all life stages, between the simulations using a fixed Manning value calibrated at low discharge and at high discharge. These differences can lead to various conclusions about mitigation measures of hydropeaking, notably on the acceptable maximum turbine discharge.

These results emphasize first the importance to measure water levels at several discharges to perform reliable modeling of fish habitat over a wide range of discharge. Then, if a fixed value of Manning is not satisfactory, it is possible to use either a linear interpolation of Manning coefficient (series " $n$ interp" in figure 5 and 6) or a law based on the calibrated roughness height (series " $\mathrm{k}=$ ") $[7,8,9]$. At station 1 , these two methods provide close results even though the law based on the calibrated roughness height is easier to implement in model and more physical. But at station 2, the interpolation is more pertinent for the reasons described above. 

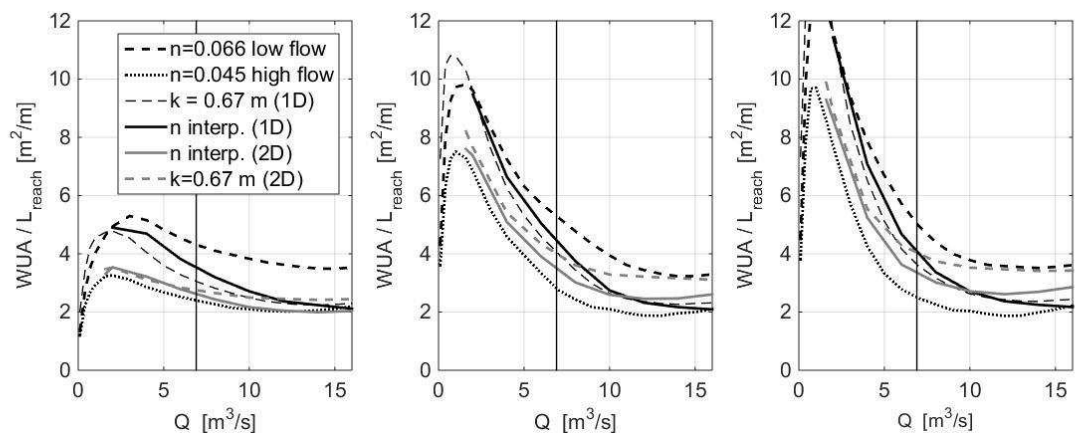

Figure 5: WUA as a function of the discharge for the station 1 for different bed friction methods. Vertical line represents the annual averaged discharge. Left: adult, center: juvenile, right: alevin.
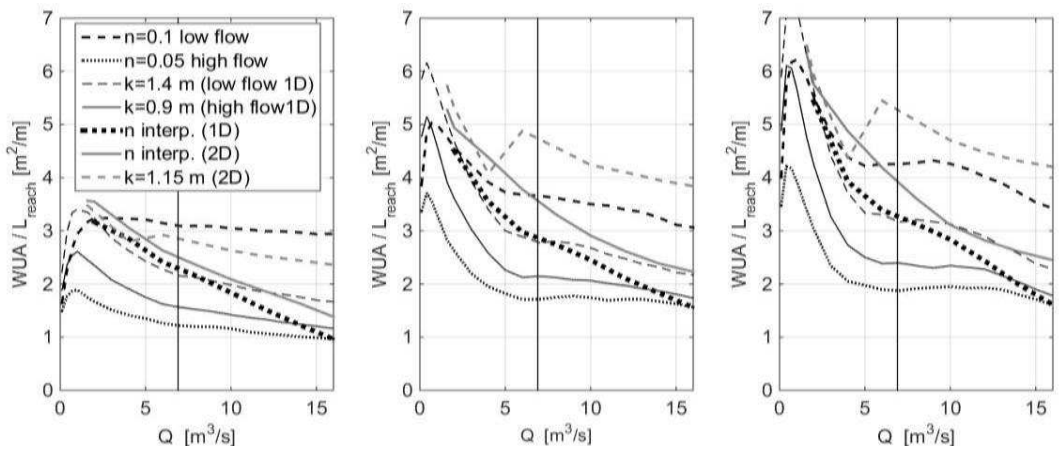

Figure 6: WUA as a function of the discharge for the station 2 for different bed friction methods. Vertical line represents the annual averaged discharge Left: adult, center: juvenile, right: alevin.

At station 2, the overflowing in the right bank is clearly detectable from $\mathrm{Q}=6 \mathrm{~m}^{3} / \mathrm{s}$, particularly for juvenile and alevin, inducing a peak for the last method $(\mathrm{k}=1.15)$ and curves with smaller slope for the other methods. This trend is due to the additional flooded area where velocity is low and favorable to small fish. With the Nikuradse law (with k) and 2D computations, the velocity is computed in each node with a specific friction which can explain the large differences between constant manning constant vs. a constant roughness height.
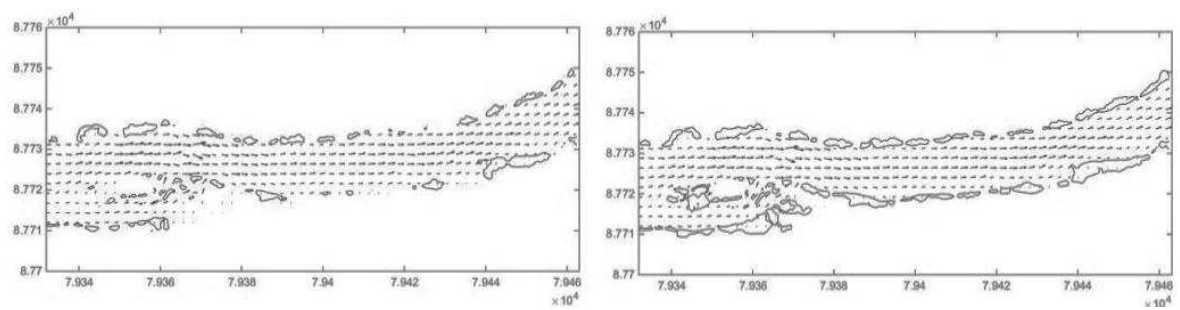

Figure 7: Velocity field and area with $S_{v} S_{h}>0.5$ for alevin at station $2 \mathrm{Q}=16 \mathrm{~m}^{3} / \mathrm{s}$, Manning calibrated at high flow ( $\mathrm{n}=0.05)$ (up) and Nikuradse method $(\mathrm{k}=1.15)$ (down)

On the figure 7, it appears that the suitable areas at high discharge $\left(16 \mathrm{~m}^{3} / \mathrm{s}\right)$ for alevin (with $S_{v} S_{h}>0.5$ ) are near the bank and within the additional flooded area. The 2 friction 
methods, Manning calibrated at high flow and Nikuradse method, lead to significant differences since the suitable area is roughly twice with the second method $\left(4.2 \mathrm{~m}^{2} / \mathrm{m}\right.$ and $2.5 \mathrm{~m}^{2} / \mathrm{m}$ ) because velocity on overbanks is larger than with the first method. This results show the importance of an effective hydraulic modelling to assess the habitat suitability. Let us note that, in our case, the Nikuradse method is very sensitive to the actual granulometry on overbanks. These results emphasize that the spatial variability of roughness height is crucial for a relevant estimation of WUA.

\section{Conclusion}

In this study, the microhabitat method has been applied using 1D and 2D hydraulic models calibrated with several methods (at low, intermediate or high discharge, linear interpolation or physically based model), corresponding to available tools used for engineering purposes. Two types of river morphology are tested and lead to two different conclusions.

When the channel has a regular shape i.e a slight variation of the top width as a function of water depth, the 1D model and 2D model provide very similar hydraulic results. The bed friction can be given by a friction law based on one roughness $k$ obtained for low or high discharge.

When several breaches are present and overflowing occurs in banks, the 2D model is more pertinent for calibration. The Manning coefficient has to be calculated by interpolation of two extremum discharges. The $2 \mathrm{D}$ method with Nikuradse law can be more perform ant if the spatial distribution of bed gradation is known.

Considering manning as a constant for all discharges can lead to different conclusions on habitat suitability only if the whereas other bed friction methods provide the same trends of the WUA curves. The roughness height depends on the law friction used and can be very different from the medium grain (or cobble) size. More extensive studies are needed to evaluate methodologies using measured diameters in situ. Finally, to perform relevant habitat modelling, it is necessary to measure water levels at several discharges and to describe accurately the spatial variability of roughness height.

\section{Acknowledgement}

We thank EDF Company and ECOGEA for providing topographic data and in situ measurements.

\section{References}

1. I.G. Jowett, Maurice J. Duncan, Ecol. Eng., 48, 92-100, (2012)

2. D.W Crowder, P Diplas, J. Hydrol, 230 (3-4), Pages 172-191, (2000).

3. V. Ginot, Y. Souchon, H. Capra, P. Breil, S. Valentin, EVHA, guide méthodologique. Cemagref Lyon (1998)

4. Benjankar R., Tonina D., and McKean , J. Earth Surf. Process. Landforms, 40, 340356 (2015)

5. C. Ducos, master thesis, ECOGEA-Univ. of Sciences and tech. of Hanoi- INPT (2016)

6. U.S. Army Corps of Engineers, Hydrologic Engineering Center, 2016, HEC-RAS hydraulic reference manual, version 5.0.

7. Nikuradse, J. Laws of Flow in Rough Pipes; National Advisory Committee for Aeronautics: Washington, DC, USA, (1933).

8. Limerinos, J. Determination of the Manning Coefficient from Measured Bed Roughness in Natural Channels; U.S. Geoeological Survey: Tacoma,Washington, USA, 1970.

9. R. Ferguson, Water Resour. Res., 43, W05427 (2007) 